Valentina Peterkova*, Kosigina A. V.

\title{
DOKTRINA I ISKUSTVO PROGRAMA PREVENCIJE I LEČENJA GOJAZNOSTI KOD ADOLESCENATA U RUSKOJ FEDERACIJI
}

Sažetak: U 21. veku gojaznost je postala jedan od najozbiljnijih zdravstvenih problema u celom svetu. Srazmere prekomerne telesne mase i gojaznosti u razvijenim zemljama neretko se porede sa epidemijskim. Posebno alarmantna tendencija prisutna je kod dece i adolescenata $u$ kojih je učestalost gojaznosti u neprekidnom porastu. Prema rezultatima epidemioloških ispitivanja dijagnoza prekomerne telesne mase kod dece u različitim regionima Rusije kreće se između 5,5 i 11,8\%, dok je gojaznost prisutna u 5,5\% dece iz seoske i 8,5\% - iz gradske sredine.

Dečija gojaznost nosi sa sobom kako kratkoročne, tako i dugoročne negativne posledice po fizičko i psihosocijalno zdravlje, i u velikoj meri predstavlja faktor rizika nastanka kardio-vaskularnih oboljenja, dijabetesa, ortopedskih problema i psihičkih poremećaja. Rezultati naših ispitivanja ukazuju da se kod gojaznih devojčica u 80\% slučajeva gojaznost održava, a u $61 \%$ slučajeva i progredira u odraslom dobu. Kod žena ove grupe, u poređenju sa ženama normalne telesne mase, češće su bile prisutne izražene promene reproduktivnog zdravlja (besplodni brakovi, teže održavanje trudnoće i komplikacije u trudnoći i kod porođaja).

Poslednjih godina primetan je porast učestalosti dijabetesa tipa 2 u dečjem uzrastu, povezanog sa gojaznošću. U Ruskoj Federaciji se od 1996. godine sprovodi program „Diabetes Mellitus”, u kojem je diabetes tipa 2 kod dece jedan od potprograma.

Prioritetni vektor naših ispitivanja je izučavanje patofizioloških mehanizama razvoja gojaznosti i udruženih poremećaja. Ispitivana je ekspresija gena koji su asocirani sa razvojem gojaznosti i diabetesa tipa 2 (ADIPOQ, PBEF1, CNP1, PPARG) u visceralnom i potkožnom depou masnog tkiva, kao i analiza kliničkog značaja adipokina - hormona adipoznog

* Pedijatrijski endokrinološki institut, Moskva, Ruska Federacija. 
tkiva - adiponektina i visfatina. Primećeno je da nivo adiponektina progresivno opada sa pojavom polne zrelosti i ima negativnu korelaciju sa vrednostima ITM i obima struka. Kod dečje gojaznosti smanjen je nivo adiponektina u serumu, posebno izražen u slučaju postojanja insulinske rezistencije. Nivo visfatina u krvi nije asociran sa vrednošću ITM kod dece, ali je povezan sa procentnim sadržajem masnog tkiva. U grupi dece sa gojaznošću i insulinskom rezistencijom taj odnos je statistički značajno viši.

Razlika u nivou ekspresije gena u potkožnom i visceralnom masnom tkivu primećena je samo kod gena visfatina (PBEF1), koji je daleko više predstavljen u visceralnom masnom tkivu; pri tom nivo ekspresije gena adipokina zavisi od ekspresije receptora PPARG1, PPARG2 i 2CNR1. $\mathrm{U}$ isto vreme nivo adipokina u serumu krvi direktno ne zavisi od nivoa ekspresije njihovih gena u masnom tkivu.

U okviru programa borbe sa dečjom i adolescentnom gojaznošću radi se na razradi novih dijagnostičkih algoritmova i protokola posmatranja i praćenja dece sa različitim formama gojaznosti (,obična”, konstitucionalna gojaznost, hipotalamusna gojaznost, sindromske forme).

Velika pažnja u programu poklanja se razradi metoda medikamentne i nemedikamentne terapije. Ispituju se različite varijante dijetoterapije (ketogena dijeta, dijeta sa manjkom ugljenih hidrata). Sprovode se klinička ispitivanja efikasnosti i bezbednosti farmakoterapije gojaznosti kod adolescenata.

В XXI веке ожирение стало одной из наиболее серьезных проблем общественного здравоохранения во всем мире. Масштабы распространенности избыточной массы тела и ожирения в развитых странах нередко сравнивают с эпидемией. Особенно тревожная тенденция наблюдается среди детей и подростков. Ежегодные темпы роста показателей распространенности ожирения среди детей и подростков непрерывно увеличиваются и по данным ВО3, в настоящее время до десяти раз превышают уровень 1970г. Нарастание числа детей с ожирением и избыточной массой тела происходит также и в России. В связи с этим профилактика и лечение ожирения и избыточной массы тела у детей является неотложной задачей педиатрической службы нашей страны.

По данным эпидемиологических исследований, в Российской Федерации распространенность избыточной массы тела у детей в разных регионах России колеблется от 5,5 до $11,8 \%$, а ожирением страдают 5,5\% детей, проживающих в сельской местности, и $8,5 \%$ детей - в городской.

Детское ожирение влечет за собой как краткосрочные, так и долгосрочные неблагоприятные последствия для физического и психосоциального здоровья, и во многом является фактором риска для развития сердечно- 
сосудистых заболеваний, диабета, ортопедических проблем и психических расстройств.

Наиболее частые метаболические нарушения, встречающиеся при ожирении у детей, согласно данным литературы — нарушения липидного обмена и инсулинорезистентность. С целью оценки частоты встречаемости метаболических осложнений ожирения и метаболического синдрома было обследовано 116 детей и подростков (65 мальчиков, 51 девочка), обратившихся в ФГУ ЭНЦ с жалобами на избыточную массу тела, 12,8 $2,8(5,9-17,5)$ лет, с ИМТ $31,8 \div 5,6(20,5-48,5)$ кг/м2 и SDS ИМТ $3,1 \div 0,6$ $(2,1-4,7)$. По результатам проведенных нами исследований, дислипидемия выявлена у $65 \%$ детей с простым ожирением, причем из них у $56 \%$ повышен уровень триглицеридов и снижен - ЛПВП, а у остальных $44 \%$ отмечается гиперхолестеринемия и повышенный уровень ЛПНП; при этом $30 \%$ детей с простым ожирением имеют дислипидемию типа 2б, связанную с гипертриглицеридемией, гиперхолестеринемией, высоким уровнем ЛПНП и низким уровнем ЛПВП. Инсулинорезистентность среди обследованных детей с ожирением выявлена у 44,4\% детей с простым ожирением. Полный симптомокомплекс метаболического синдрома был диагностирован у $45 \%$ пациентов, один критерий МС имелся у $29 \%$, а сочетание 2-х критериев - у $26 \%$ обследованных. Частота встречаемости нарушенной толерантности к глюкозе (НТГ) среди этих детей составила $21 \%$. Таким образом, можно сказать, что в выборке среди детей и подростков со степенью ожирения $3,1 \div 0,6$ SDS ИМТ у каждого второго ребенка имеется метаболический синдром, а каждый пятый имеет нарушение углеводного обмена в виде НТГ.

Исследования, проведенные в нашем центре, показали, что у девочек с ожирением в $80 \%$ оно сохранялось и в $61 \%$ прогрессировало во взрослой жизни. У этих женщин чаще, чем у женщин без ожирения, отмечались значительные изменения со стороны репродуктивного здоровья (бесплодные браки, невынашивание беременности, осложнения беременности и родов).

Одним из приоритетных направлений исследований является изучение патофизиологических механизмов развития ожирения и ассоциированной с ним патологии. В настоящее время активно обсуждается самостоятельная роль жировой ткани в патогенезе ожирения и связанных с ним осложнений. Исследования последних лет показали, что жировая ткань приспособлена не только к накоплению энергии в виде триглицеридов, но и секретирует целый ряд активных молекул - адипокинов, влияющих на потребление пищи, метаболические процессы, нарушения со стороны сердечно-сосудистой системы, т.е. обладающих различными локальными, периферическими и центральными эффектами. Кроме того в жировой ткани экспрессируется большое количество рецепторов, транскрипционных факторов и ферментов, регулирующих процессы адипогенеза и вовлеченных в патогенез ожирения 
и сахарного диабета 2 типа. Важное значение имеет не только факт наличия ожирения и его степень, но и характер распределения жира. Активно изучается роль висцерального и подкожного депо в развитии тех или иных метаболических нарушений, инсулинорезистентности и сахарного диабета 2 типа у детей и подростков.

Нами проведено исследование по изучению экспрессии генов, ассоциированных с развитием ожирения и СД 2 (ADIPOQ, PBEF1, CNR1, PPARG) в висцеральном (ВЖТ) и подкожном (ПЖТ) депо жировой ткани, а также анализ клинической значимости адипокинов - гормонов жировой ткани - адипонектина и висфатина. Выявлено, что уровень адипонектина сыворотки крови прогрессивно снижается по мере полового созревания у детей и отрицательно коррелируется с показателями ИМТ и ОТ. При ожирении у детей отмечается снижение уровня адипонектина сыворотки крови, особенно выраженное при наличии инсулинорезистентности. Уровень висфатина сыворотки крови не ассоциирован с показателем ИМТ у детей, но взаимосвязан с процентным содержанием жировой ткани и статистически значимо выше в группе детей с ожирением, осложненном инсулинорезистентностью. Различия в уровне экспрессии генов между подкожной и висцеральной жировой тканью были выявлены только для гена висфатина (PBEF1), который более высоко экспрессируется ВЖТ, при этом уровень экспрессии генов адипокинов взаимосвязан с экспрессией генов рецепторов PPARG1 и PPARG 2, CNR1, но в то же время уровень адипокинов сыворотки крови не находится в прямой зависимости от уровня экспрессии их генов жировой тканью.

Наименее изученным среди всех форм ожирения остается гипоталамическое ожирение, связанное с лечением опухолей гипоталамуса и ствола мозга, лучевой терапией опухолей головного мозга и гемобластозов, травмой черепа или инсультом. Несмотря на то, что этот термин используется очень давно, описание механизмов и его отличие от других форм ожирения практически отсутствует. Считается, что в патогенезе данной формы ожирения ведущую роль играет повреждение вентромедиального гипоталамуса, в результате чего усиливается стимулирующее влияние вагуса на бета-клетки поджелудочной железы, развивается стойкая гиперинсулинемия, приводящая к гиперфагии и ожирению. Инсулинорезистентность выявлена нами у 41,2\% пациентов с гипоталамическим ожирением. Следует отметить, что все пациенты с гипоталамическим ожирением имели дислипидемию: у 47\% нарушения липидного спектра крови были связаны с высоким уровнем триглицеридов, низким уровнем ЛПВП в сочетании с нормальным или повышенным уровнем ЛПНП; у $12 \%$ отмечался высокий уровень ЛПНП с гиперхолестеринемией, а у $41 \%$ гипертриглицеридемия, высокий уровень ЛПНП и низкий ЛПВП сочетались с гиперхолестеринемией. Таким образом, частота встречаемости дислипидемии среди детей с гипоталамическим ожирением составила $100 \%$, 
что может быть связанно с вторичным дефицитом СТГ, который наблюдается практически у всех пациентов после оперативного лечения. МС встречался в группе детей с гипоталамическим ожирением с той же частотой, что и в группе детей с простым ожирением - 41\%.

Учитывая выраженную гиперинсулинемию, лежащую в основе патогенеза гипоталамического ожирения, нами было исследовано применение пролонгированного аналога соматостатина - октреотида (Сандостатин ЛАР) в этой группе больных. На фоне терапии Сандостатином ЛАР наблюдалось достоверное выраженное снижение гиперинсулинемии (на 65\%) и инсулинорезистентности; но это не сопровождалось значимыми изменениями веса и дислипидемии. Кроме того, у 71\% пациентов отмечалось образование камней в желчном пузыре, 57\% пациентов развили нарушения углеводного обмена в виде нарушенной толерантности к глюкозе и у 28,5\% наблюдался диспептический синдром, что ограничивает применение Сандостатина ЛАР в лечении гипоталамического ожирения у детей.

Очевидно, что ожирение у детей является мультифакторным заболеванием с наследственной предрасположенностью, которая на $30-50 \%$ может обуславливать склонность к избыточной массе тела. Всего в публикациях последних лет описано более 430 генов, маркеров и хромосомных участков, связанных с ожирением у людей. Среди редких форм ожирения можно выделить две группы - синдромы, сочетающиеся с развитием ожирения, и моногенные формы ожирения.

Одной из часто встречаемых форм синдромального ожирения является синдром Прадера-Вилли. Приблизительно 70\% случаев синдрома ПрадераВилли обусловлено делецией, 20-28\% - материнской дисомией участка 15 хромосомы 15 q11-q12, в оставшихся 2-5\% случаях причиной синдрома является мутация импринтингового центра, наследуемая по аутосомно-доминантному типу. В нашем центре накоплен опыт наблюдения за детьми с этой патологией, проводится исследование эффективности и безопасности терапии препаратами рекомбинантного гормона роста.

Из известных гетерозиготных мутаций, достоверно связанных с развитием ожирения, наиболее распространенными являются мутации генов лептин-меланокортинового пути - LEP, LEP-R, POMC, MC4-R, CART. Нами был описан клинический случай пациента с врожденным дефицитом проопиомеланокортина (мутация в гене POMC 2p23.3). В клинической картине было выявлено сочетание вторичной надпочечниковой недостаточности с неопределяемыми в сыворотке крови уровнями АКТГ, предшественником которого является проопиомеланокортин, и кортизола и быстропрогрессирующего ожирения на фоне полифагии.

С учетом полиэтиологического характера ожирения и значительного числа факторов, лежащих в основе его развития, профилактика и лечение ожирения и избыточной массы тела у детей должна носить комплексный характер, включающий не только медицинские, но и социальные аспекты, в частности, коррекцию 
питания, вопросы повышения физической активности детей, рекламы продуктов питания, производства продуктов здорового питания.

Важное место уделяется разработке комплексных методов медикаментозной и немедикаментозной терапии, направленных на нормализацию массы тела и предотвращение ее дальнейшего нарастания с возрастом. Основным клиническим подходом к лечению ожирения в подростковом периоде является поведенческая терапия, направленная на изменение питания и увеличение физической активности. Исследуются различные варианты диетотерапии (низкоуглеводная кетогенная диета, диета с низким содержанием жира). Было проведено исследование применения низкоуглеводной кетогенной диеты у 15 детей-подростков, страдающих первичным конституциональным ожирением 1-3-й степени. Критериями оценки являлись динамические изменения веса, липидной фракции крови, динамические изменения в процентном содержании жира по данным денситометрии «Total body», изменения индексов инсулинорезистентности. Полученные данные свидетельствуют, что данный вид лечебной диеты хорошо переносится детьми, нормализуются значения холестерина, триглицеридов, $\beta$-липопротеидов в сыворотке крови, снижаются индексы инсулинорезистентности на фоне эффективного снижения веса и аппетита.

Ведутся клинические исследования эффективности и безопасности фармакотерапии ожирения в подростковом возрасте.

Нами продемонстрирована эффективность и безопасность длительной, 12-месячной терапии метформином осложненного ожирения у детей. На фоне применения метформина в дозе 1000 мг/сутки наблюдалось достоверно значимое

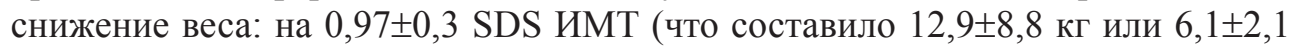
ИМТ), что сопровождалось достоверными выраженными изменениями липидного и углеводного обмена: снижением гиперинсулинемии на 57\% и инсулинорезистентности; нормализацией липидного спектра крови и гликемического профиля при одновременном снижении уровня лептина на $42 \%(\mathrm{p}<0,01)$ и увеличения уровня ИРФ-1 на $0,77 \pm 0,18 \operatorname{SDS}(\mathrm{p}<0,01)$. Многофакторность фармакологического действия метформина в сочетании с хорошей переносимостью позволяют рекомендовать включение данного препарата в комплексную терапию осложненного ожирения у детей и подростков.

Было проведено клиническое исследование эффективности и безопасности применения орлистата (Ксеникал) в комплексной терапии ожирения и метаболических нарушений у подростков старше 12 лет. При применении орлистата в течение 6 месяцев в дозе 120 мг 3 раза в сутки отмечался более значительный клинический эффект по сравнению с группой контроля (гипокалорийная диета и аэробные нагрузки). Так в группе детей принимавших препарат отмечалось

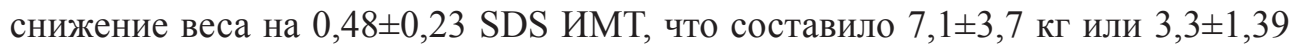
кг $/ \mathrm{M}^{2}$, в то время как в группе контроля $\Delta$ SDS ИМТ составила $-0,17 \pm 0,27$ ( $<$ $0,01)$, уменьшение окружности талии на $6,1 \pm 5,5$ см против $0,43 \pm 4,75$ см в группе 
контроля $(\mathrm{p}=0,03)$, снижение процентного содержания жировой ткани, оце-

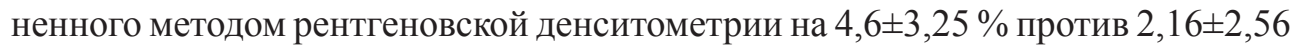
$\%(\mathrm{p}=0,04)$. Вместе с этим отмечались статистически значимые изменения со стороны нарушений углеводного и жирового обмена: значительное снижение базальной (на 49\%) и стимулированной (на 41\%) инсулиносекреции, нормализация гликемии, снижение уровней общего холестерина и ЛПНП. Была отмечена хорошая переносимость препарата у большинства пациентов. Среди побочных эффектов у части больных отмечались частый стул, метеоризм в первые недели приема препарата, что потребовало отмены препарата только у одного пациента включенного в исследование.

Ожирение - хроническое состояние, и в идеале терапия требует усилий не только одного врача и самого пациента, а также семьи, окружения ребенка и целой команды специалистов, включая психологов, диетологов, эндокринологов. А лучшей тактикой борьбы с ожирением можно считать его профилактику и именно на это должны быть направлены основные силы здравоохранения. 